Jeffrey E. Fletcher PH D, Henry Rosenberg MD, Merrill Hilf BA

\title{
Effects of midazolam on directly stimulated muscle biopsies from control and malignant hyperthermia positive patients
}

Midazolam is a water soluble benzodiazepine of interest to the anaesthetist for use as a premedicant and for induction of anaesthesia. The effects of midazolam were observed on the resting tension of directly stimulated muscle biopsied from control and malignant hyperthermia (MH) susceptible patients. In addition, interactions between midazolam and the two most commonly used $M H$ diagnostic agents (halothane and caffeine) were examined. Midazolam, at maximum therapeutic concentrations (ca. $0.5 \mu \mathrm{g} \cdot \mathrm{ml}^{-1}$ ), had no detectable effects on muscle contraction in preparations from control or $\mathrm{MH}$ positive patients. Midazolam did elict a contracture from control and $M H$ positive prepurations when used in a concentration range of $160-1280 \mu \mathrm{g} \cdot \mathrm{ml}^{-1}$. There was no significant difference between control and $M H$ positive patients in minimum concentration of midazolam causing contracture or the strength of contracture at the respective eliciting concentration. There appears to be no interaction between midazolam and either halothane or caffeine on the resting tension of the directly stimulated muscle iwilch preparation.

Key words

HYPERTHERMTA: malignant; ANAESTHFTICS, INTRA VENOUS: midazolam; HYPNOTICS: benZodiazepines; MUSCLE, SKELETAL: contraction, drug effects.

From the Laboratory for the Study of Malignant Hyperthermia, Department of Anaesthesiology, Hahnemann University, Philadelphia.

Address correspondence to: Dr. H. Rosenberg, Dept. of Anesthesiology MS-310, Hahnemann University, Broad and Vine, Philadelphia, PA 19102.

Supported by a grant from Hoffmann-LaRoche, Inc., Nutley, NJ

CAN ANAESTH SOCJ $1984 / 31: 4 /$ pp 377-81
Anaesthesia-induced malignant hyperthermia $(\mathrm{MH})$ is a potentially fatal pharmacogenetic disorder associated with the use of certain anaesthetic agents in a susceptible population. The syndrome is characterized by pyrexia, muscle rigidity, acidosis and hypermetabolism during or following anaesthesia. ${ }^{1}$ The diagnosis is further strengthened if serum creatine phosphokinase (CPK) is elevated ${ }^{2,3}$ and evidence of muscle destruction can be found following recovery from the acute phase of $\mathrm{MH}^{4}$ The clinical diagnosis is made difficult because the full syndrome is not always manifested. In thosc cases where anaesthesia is stopped because of these early signs, or in relatives of MH patients, the identification of $\mathrm{MH}$ susceptibility by in vitro diagnostic means is desirablc. . $^{2,6}$

The MH episode can be triggered by a wide variety of agents having different modes of action. ${ }^{7}$ Because the response is so severe, it is desirable that any agents used for surgery with these patients be screened for their $\mathrm{MH}$ syndrome eliciting potential. Currently there are no accepted methods for screening agents for the potential of producing $\mathrm{MH}$ other than clinical trials.

The most widely accepted diagnostic method for determining $\mathrm{MH}$ susceptibility is the in vitro contracture response of biopsied skeletal muscle to halothane and/or caffeine as used in our laboratory. ${ }^{5}$ The observed response (miscle contracture) is assumed to refiect enhanced myoplasmic $\mathrm{Ca}^{2+}$ available to the contractile apparatus. ${ }^{8}$ Halothane is used in these studies as it is the most common triggering agent for the $\mathrm{MH}$ syndrome in the clinical setting. ${ }^{7}$ Caffeine is used to elevate cytoplasmic $\mathrm{Ca}^{2+}$ concentrations artificially and thereby determine the capacity of the tissue to react to $\mathrm{Ca}^{2+}$ 
overload. In our laboratory MH susceptibles differ from nonsusceptibles in that their muscles develop contractures of greater than $0.5 \mathrm{~g}$ to less than two per cent halothane. The muscles from MH patients also develop greater than $0.3 \mathrm{~g}$ contracture upon exposure to $2 \mathrm{mM}$ caffeine. Muscle strips from control patients typically do not respond with contracture to halothane and develop contractures only to higher concentrations of caffeine. ${ }^{5}$ The in vitro contracture response of biopsied human skeletal muscle is one method of determining if $\mathrm{MH}$ susceptibles respond differently than controls to various agents. Although clinical trials remain the only means of determining the potential of an agent to produce $\mathrm{MH}$, in vitro testing should provide important preliminary information as to the safety of agents used in anaesthesia.

We investigated the effects of midazolam on biopsied human skeletal muscle preparations from control and $\mathrm{MH}$ positive patients to screen for the production of abnormal contracture responses. In addition, we examined for the existence of interactions between midazolam and halothane or caffeine.

\section{Methods}

\section{Human muscle biopsies}

Potential MH patients were selected for biopsy based on suspicion of $\mathrm{MH}$ according to communications from referring physicians. A questionnaire was filled out by the patient or his family detailing family history, particularly with regard to muscle disease. The patients were then diagnosed as $\mathrm{MH}$ positive or $\mathrm{MH}$ negative (control) based on the halothane and caffeine contracture tests, described below. In addition, biopsies from patients undergoing operations for reasons unrelated to skeletal muscle disorders or those with known skeletal muscle disorders, but with no indications of $\mathrm{MH}$, were used as healthy and disease controls, respectively.

Muscle biopsies were done with femoral and lateral fermoral cutaneous blocks, avoiding infiltration of the muscle with the anaesthetic. In children, biopsies were frequently obtained under general anaesthesia using non-triggering agents.

\section{Caffeine contracture test}

The muscle used in these tests was the vastus lateralis. Dimensions of the muscle strips were
$0.5-3.0 \mathrm{~cm}$ (length) by $2.0-6.0 \mathrm{~mm}$ (width) by 1-2 mm (thickness). The muscle was immediately placed into Krebs Ringer solution composed of $\mathrm{NaCl} 118 \mathrm{mM}, \mathrm{KCl} 3.4 \mathrm{mM}, \mathrm{MgSO}_{4} 0.8 \mathrm{mM}$, $\mathrm{KH}_{2} \mathrm{PO}_{4} 1.2 \mathrm{mM}$, glucose $11.1 \mathrm{mM}, \mathrm{NaHCO}_{3}$ $25.0 \mathrm{mM}$ and $\mathrm{CaCl}_{2} 6 \mathrm{H}_{2} \mathrm{O} 2.5 \mathrm{mM}$. The $\mathrm{pH}$ was adjusted to 7.4 and curare $20.0 \mu \mathrm{M}$ was added. The muscle was transported to the laboratory in Krebs Ringer solution at room temperature. In the laboratory the test was done at $37^{\circ} \mathrm{C}$, in Krebs Ringer solution through which $\mathrm{O}_{2}: \mathrm{CO}_{2}(95: 5)$ was bubbled. The maximum ischaemia time from excision of the muscle to isometric mounting in the tissue bath was five hours.

The muscle was stimulated at $0.2 \mathrm{~Hz}$ with a pulse duration of two to ten msec and at supramaximal voltage. The preparation was adjusted to an initial resting tension of $2.0 \mathrm{~g}$. The final concentrations of caffeine were $0.5,1.0,2.0,4.0,8.0,16$ and $32 \mathrm{mM}$. Each successive dose of caffeine was added as soon as the contracture plateau induced by the previous concentration of caffeine had been reached. In the event that no contracture was observed during a two-minute period, the next concentration of caffeine was added. The contracture amplitude is the change in resting tension (in grams) from the baseline preceding drug administration to the peak value following drug addition.

\section{Halothane contracture test}

The muscle was prepared as for the caffeine contracture test. Halothane one or two per cent in 95 per cent $\mathrm{O}_{2}: 5$ per cent $\mathrm{CO}_{2}$ was then bubbled through the chamber. The halothane concentration was determined by gas chromatography. Time of halothane exposure was at least $5 \mathrm{~min}$ or until a maximum contracture was observed. Size of contracture was determined as in the caffeine test.

\section{Midazolam contracture test}

The muscle was prepared as for the caffeine contracure test. Successive concentrations of midazolam were added to the bath in the same manner as the cafleine contracture test. Midazolam was dissolved in Krebs Ringer.

\section{Data analysis}

Data were gathered "on line" using a microcomputer systern. Data were analyzed using a one-way analysis of variance. Since no significant differ- 
ences were observed between groups, no further analysis was undertaken.

\section{Results}

\section{Diagnosis}

Patients were diagnosed as $\mathrm{MH}$ susceptible by the response of directly stimulated biopsied skeletal muscle to halothane and caffeine alone and in combination, as previously described. ${ }^{5}$ Three categories resulted from the in vitro diagnosis:

1 Controls (six patients). Those patients with no indication of $\mathrm{MH}$ potential, as determined by the absence of a significant contracture following exposure to halothane (one to two per cent) and/or caffeine ( $\leqslant 2 \mathrm{mM}$ ) during the in vitro contracturc screen. These patients also had no known muscular disease. This group included patients with a family history of $\mathrm{MH}$, but who were judged $\mathrm{MH}$ negative using the in vitro contracture test. Also included were patients with no known family history of MH.

2 DISEASE CONTROLS (six patients). Those with no indication of $\mathrm{MH}$ potential (see controls), but who had known muscular disease.

3 MALIGNANT hYPERTHERMIA POSITIVES (nine patients). Those patients with an indication of $\mathrm{MH}$ susceptibility, as judged by the presence of significant contracture upon exposure to halothane and/or caffeine during the in vitro muscle contracture screen.

\section{Minimum concentration of midazolam to elicit contrature}

There was no effect of midazolam on the muscle preparation in the therapeutic range of approximately $0.5 \mu \mathrm{g} \cdot \mathrm{ml}^{-1}$ peak plasma concentration. ${ }^{9}$ Therefore, we examined the effects of higher doses of midazolam to determine if any toxic action on directly stimulated muscle resting tension could be observed. The effects of midazolam in concentrations of $10,20,40,80,160,320,640$ and $1280 \mu \mathrm{g} \cdot \mathrm{ml}^{-1}$ on the in vitro contracture test were determined. Midazolam, in a concentration range of $160-1280 \mu \mathrm{g} \cdot \mathrm{ml}^{-1}$ did evoke a contracture from the muscle preparation. We then examined muscle preparations from $\mathrm{MH}$ positives to see if these patients might have a greater susceptibility to this "toxic" effect of midazolam. The results, by group, are as follows:

1 ConTrol. Midazolam at concentrations up to
TABLE I Minimum concentration of midazolarn eliciting muscle contracture.

\begin{tabular}{ll}
\hline Preparation & $\begin{array}{l}\text { Midazolam concentration } \\
\left(\mu g \cdot \mathrm{t}^{-1}\right)\end{array}$ \\
\hline Control & $733 \pm 178(6)$ \\
Disease control & $587 \pm 221(6)$ \\
MH positives & $640 \pm 131(9)$ \\
\hline
\end{tabular}

Values expressed as mean \pm SEM (n).

Note: Muscle biopsy preparations were directly stimulated in Kreb's solution containing midazolam at increasing concentrations. The lowest concentration at which midazolam elicited cantracture is shown.

$80 \mu \mathrm{g} \cdot \mathrm{ml}^{-1}$ exerted no detectable effects on directly stimulated muscle resting tension. The concentration of $80 \mu \mathrm{g} \cdot \mathrm{ml}^{-1}$ is about 160 times the peak plasma concentration necessary for induction of anaesthesia. ${ }^{9}$ Muscle contractures were observed for control preparations in a range of midazolam concentrations of $160-1280 \mu \mathrm{g} \cdot \mathrm{ml}^{-1}$ (Table I).

2 DISEASE CONTROL. Disease control values for minimum concentration necessary to cause muscle contracture also had a range of $160-1280 \mu \mathrm{g} \cdot \mathrm{ml}^{-1}$. There was no significant difference between control and disease control preparations in regard to this parameter (Table I).

3 malignant hyperthermia positives. The range of values for minimum concentration of midazolam necessary to cause contracture for the $\mathrm{MH}$ positive group was $320-1280 \mu \mathrm{g} \mathrm{ml}^{-1}$. There was no significant difference between either control group or the $\mathrm{MH}$ positive group (Table I).

Strength of contracture at minimum concentration of midazolam causing contracture

It was possible that the contractions occurring at the lowest eliciting concentrations for $\mathrm{MH}$ positive preparations might be of greater amplitude than those of control preparations. Therefore, we examined the effects of midazolam on this parametcr using muscle strips from the three patient populations.

1 conTrol. Control values for strength of contracture at minimum eliciting concentrations exhibited a range of $0.2-3.2 \mathrm{~g}$ (Table II).

2 DISEASE CONTROL. The range of values for disease control preparations was similar to contro]s $(0.1-1.7 \mathrm{~g})$. There was no significant difference between control and disease control preparations (Table II). 
TABLE II Strength of contracture at minimum eliciting concentration of midazolam.

\begin{tabular}{ll}
\hline Prepararion & $\begin{array}{l}\text { Increase in resting } \\
\text { Tension }(g)\end{array}$ \\
\hline Control & $1.7 \pm 0.6(6)$ \\
Disease control & $0.7 \pm 0.3(6)$ \\
MH pusitives & $1.0 \pm 0.3(9)$ \\
\hline
\end{tabular}

Values expressed as mean \pm SEM (n).

Note: Muscle biopsy preparations were directly' stimulated

in Krebs solution containing midazolam at increasing concentrations (see Results).

3 malignant hyPERTHERMIA POSITIVES. The range of values for the $\mathrm{MH}$ positive group was similar to either control $(0.15-2.5 \mathrm{~g})$. No statistically significant differences were observed between either control group and the $\mathrm{MH}$ positive group (Table II).

\section{Interactions bewen midazolam and halothane}

Halothane has previously been shown to increase the sensitivity of muscle preparations to caffeine. ${ }^{10}$ We wished to determine if any interactions exist between midazolam and halothane. Preincubation of the directly stimulated muscle preparation with midazolam $10 \mu \mathrm{g} \cdot \mathrm{ml}^{-1}$ for $6 \mathrm{~min}$ had no effect on muscle tension upon subsequent exposure to halothane one to two per cent in one preparation from a control patient. Pre-exposure to halothane one per cent of two preparations from one disease control patient had no effect on the subsequently determined midazolam dose-response curve; the minimum concentration of midazolam necessary for contracture was $160 \mu \mathrm{g} \cdot \mathrm{ml}^{-1}$ in the presence or absence of halothane. Pre-exposure to halothane of two preparations from other control patients did not cause contracture when the muscles were subsequently bathed in midazolam $10 \mu \mathrm{g} \cdot \mathrm{ml}^{-1}$. One preparation from an $\mathrm{MH}$ positive patient was incubated with midazolam $1280 \mu \mathrm{g} \cdot \mathrm{ml}^{-1}$, washed and exposed to halothane 2.5 per cent. The contracture resulting from the halothane exposure $(0.3 \mathrm{~g})$ was not different from preparations from the same patient that had not previously been exposed to midazolam $(0.4 \pm 0.1$ g; mean $\pm S E M$; $\mathbf{n}=4)$.

Interactions between midazolam and caffeine Caffeine dose-response curves obtained using two preparations from a control patient, one preparation incubated with and the other without midazolam
$5 \mu \mathrm{g} \cdot \mathrm{ml}^{-1}$ did not differ. Also, the midazolam dose-response curve for a second subject in the absence of caffeine was identical to that in the presence of caffeine $4 \mathrm{mM}$.

\section{Discussion}

Control preparations were not affected by concentrations of midazolam in the therapeutic range. Higher concentrations of midazolam $\left(160 \mu \mathrm{g} \cdot \mathrm{ml}^{-1}\right.$, or about $440 \mu \mathrm{M}$ ) did exert a "toxic" action (muscle contracture) on preparations from control and $\mathrm{MH}$ positive patients. Since this contracture occurred well outside the range of therapeutic concentrations, a complete dose-response curve was not deemed necessary. The effect is most probably non-specific and clinically irrelevant for the nonsusceptible patient population. However, we did wish to determine if the $\mathrm{MH}$ positive group was more sensitive to midazolam in regard to this druginduced contracture. An enhanced responsiveness of several orders of magnitude might reflect a potential of midazolam for triggering an MH episode. There was no difference between preparations obtained from control or $\mathrm{MH}$ positive patients in regard to the concentration of midazolam eliciting contracture, or strength of contracture at the minimum eliciting concentration.

Halothane is a major $\mathrm{MH}$ syndrome triggering agent. ${ }^{7}$ We wished to determine if any interactions exist between midazolam and halothane in muscle biopsies from control patients. There were no detectable interactions of these two agents on our muscle preparation.

Caffeine releases stores of $\mathrm{Ca}^{2+}$ from the sarcoplasmic reticulum and thereby increases cytoplasmic $\mathrm{Ca}^{2+}$ concentrations, activating the contractile apparatus. ${ }^{11}$ Since alterations in $\mathrm{Ca}^{2+}$ metabolism are associated with the action of several drugs, we sought to determine if caffeine exhibits any interactions with midazolam. There were no detectable interactions of caffeine and midazolam on directly stimulated skeletal muscle preparations.

The in vitro contracture test could provide significant information in regard to the safety of drugs used for anaesthesia. However, the usefulness of this test to screen for agents with MH syndrome-eliciting potential remains to be determined. A systematic study of a large number of agents using the in vitro test remains to be conducted. The results from such a study could then be 
compared with the clinical reports of the respective drugs to determine the predictive value of the in vitro test. We are currently conducting such studies.

These studies suggest that midazolam might be a "safe" agent to use with patients susccptible to anaesthesia-induced MH. However, it is important to note that these studies were conducted using a directly stimulated muscle preparation bathed in a curare-containing medium. We chose direct stimulation as it is the most accepted method of $\mathrm{MH}$ diagnosis. Therefore, we have not examined any action of midazolam at the acetylcholine receptor or its associated ion channels, which might affect the response of $\mathrm{MH}$ muscle. Such studies remain to be conducted to evaluate further the safety of midazolam when used in $\mathrm{MH}$ positive patients.

\section{Acknowledgements}

Midazolam, 8-chloro-6 (2-fluorophenyl)-1-methylmethyl-4H-imidazo-1,5-2) ${ }^{1,4}$ benzodiazepine, free base Lot \#009111 was a gift of Hoffman-LaRoche Inc.

\section{References}

I Gronert GA. Malignant hyperthermia. Anesthesiology 1980; 53: 395-423.

2 Anderson IL, Rawstron RE, Dunlop DJ. Screening for malignant hyperthermia susceptibility. NZ Med J 1980; 91: 417-9.

3 Britt $B A$. Malignant hyperthermia: a pharmacogenetic disease of skeletal and cardiac muscle. N Engl J Med 1974; 290: 140-2.

4 Denborough MA, Dennet X, Anderson R McD. Central-core disease and malignant hyperpyrexia. Lancet 1973 ; i: $1138-40$.

5 Rosenberg H, Reed S. In vitro contracture tests for susceptibility to malignant hyperthermia. Anesth Analg 1983; 62: 415-20.

6 Nelson TE, Flewellen EH. The malignant hyperthermia syndrome. N Engl J Med 1983; 309: 416-8.

7 Britt BA. Malignant hyperthernia; a review. I $r$ : Milton, AS, ed. Handbook of Experimental Pharmacology Vol. 60. Berlin: Springer-Verlag, 1982: 547615 .

8 Britt BA, Kalow W, Gordon A, Humphrey JG, Rewcastle NB. Malignant hyperthermia: an investigation of five patients. Can Anaesth Soc J 1973; 20: $431-67$

9 Brown CR, Sarnquist FH, Canup CA, Pedley TA. Clinical, electroencephalographic, and pharma- cokinetic studies of a water-soluble benzodiazepine, midazolam maleate. Anesthesiology 1979; 50: 46770.

10 Britt BA, Endrenyi L, Frodis W, Scott E, Kalow $W$. Comparison of effects of several inhalation anaesthetics on caffeine-induced contractures of normal and malignant hyperthermic skeletal muscle. Can Anaesth Soc J 1980; 27: 12-15.

11 Sandow A. Skeletal muscle. Ann Rev Physiol 1970; 32: $87-138$

Résumé

Le midazolam est une benzodiazépine hydrosoluble pouvant être ưilisable en prémédication ou pour l' induction de l'anesthésie. On a étudié les effets du midazolam sur la tension de repos de fibres musculaires stimulées directement; les biopsies musculaires venaient de patients normaux el d'autres susceptibles à l'hyperthermie maligne. On a aussi étudié les interactions entre le midazolam et les deux agents les plus couramment employés pour le diagnostic de I'HM (halothane et caféine). Le midazolam à des concentrations thérapeu. tiques maximaies (ca. $0.5 \mu \mathrm{g} \cdot \mathrm{ml}^{-1}$ ) n'a aucun effet détectable sur la contraction musculaire des préparations normales et susceptibles a I'HM. On a montré une contracture au midazolam chez les deux groupes à des concentrations de $160-1280 \mu \mathrm{g} \cdot \mathrm{ml}^{-1}$. II n'y avait pas de différence significative entre les contrôles et les $H M$ dans la concentration minimale de midazolam amenant une contracture ou dans la force de la conrachure a la même concentration. Il n'y a pas d'interaction entre le midazolam et l' halothane ou la caféine sur la tension de repos du muscle directement stimulé. 